\title{
Pressure losses and oscillations in a compact valve of a steam turbine
}

\author{
Václav Sláma ${ }^{1,2 *}$, David Šimurda ${ }^{3}$, Lukáš Mrózek ${ }^{2}$, Ladislav Tajč², Jindřich Hálaª , and \\ Tomáš Radnic ${ }^{3}$ \\ ${ }^{1}$ Doosan Skoda Power s.r.o., Tylova 1/57, 301 28, Pilsen, Czech Republic \\ ${ }^{2}$ University of West Bohemia, Power System Engineering Department, Univerzitni 8, 306 14, Pilsen, \\ Czech Republic \\ ${ }^{3}$ Institute of Thermomechanics of the Czech Academy of Sciences, Dolejškova 1402/5, 18200 Praha \\ 8, Czech Republic
}

\begin{abstract}
Characteristics of a new compact valve design for steam turbines are analysed by measuring pressure losses and oscillations on the valve model. It is the model of an intercept valve of the intermediate-pressure turbine part. This valve is relatively smaller hence cheaper than usual control and intercept valves. Besides, four different valve seat angles were tested in order to investigate the valve seat angle influence. In order to further clarify measured phenomena, the wide range of numerical simulations were also carried out. Measurements were performed in the Aerodynamic laboratory of the Institute of Thermomechanics of the Czech Academy of Sciences in an air test rig installed in a modular aerodynamic tunnel. Numerical simulations were performed in the Doosan Skoda Power Company using a package of ANSYS software tools. Measurement results are compared with numerical and generalized in the form of valve characteristics and pressure oscillation maps. As a result of the pressure loss analysis, pressure losses in similar valve assemblies can be predicted with required accuracy for each new turbine where modern compact valves are used. As a result of the pressure oscillation analysis, operating conditions at which dangerous flow instabilities can occur were identified. Thanks to this, the areas of safe and dangerous operating conditions can be predicted so that the operational reliability of the valve can be guaranteed.
\end{abstract}

\section{Introduction}

The steam turbine governing system, which includes different types of valves, is a crucial part of any steam turbine. Therefore, the research and development of valves has a long tradition in Doosan Skoda Power Company which also cooperates with a lot of external specialist, for example from the University of West Bohemia, the Czech Academy of Sciences as well as NPO CKTI or MEI in the Russian Federation. A lot of results have been already published such as, for example, [1-8]. In this paper, a control valve of the intermediate-pressure turbine part is investigated. It is also called as an intercept valve and it

\footnotetext{
* Corresponding author: vaclav.slama@,doosan.com
} 
is shown in Fig. 1 on the left. Some results and facts can be found in [7]. Further results, especially for all tested valve seat angles $\left(60^{\circ}, 70^{\circ}, 80^{\circ}\right.$ and $\left.90^{\circ}\right)$ are described here. The original approach is especially the depicting the intensity of pressure oscillations danger in the form of pressure oscillation maps.

In compare with control valves for high pressure (HP) turbine parts, the main disadvantage of valves for intermediate-pressure (IP) turbine parts is their greater size due to the greater volumetric mass flow. It leads to more expensive design as well as severe technological and assembly issues. For this reason, the new compact valve was designed. Compact does not mean that the whole valve is smaller than usual. The smaller is only the diameter of the control valve chamber $D_{\mathrm{k}}$ in comparison with the diameter of the valve diffuser throat $D$. The scheme is shown in Fig. 1 on the right, where the typical and compact valve is compared by scaling both on the same valve diffuser throat size. The dimensions are shown in Tab. 1 where $D_{\mathrm{k}}$ is the diameter of the valve chamber, $D$ is the diameter of the diffuser throat, $\alpha$ is the valve seat angle which was tested (Fig. 2 on the right) and $D_{\mathrm{k}} / D$ is the diameter ratio which shows that the compact valve is approximately twice smaller than the typical valve. $D_{\mathrm{k}}, D$ and $\alpha$ are also shown in Fig. 2 on the left. Due to this compactness, the valve is cheaper and there are no serious technological issues. However, the pressure losses are expected to be greater.
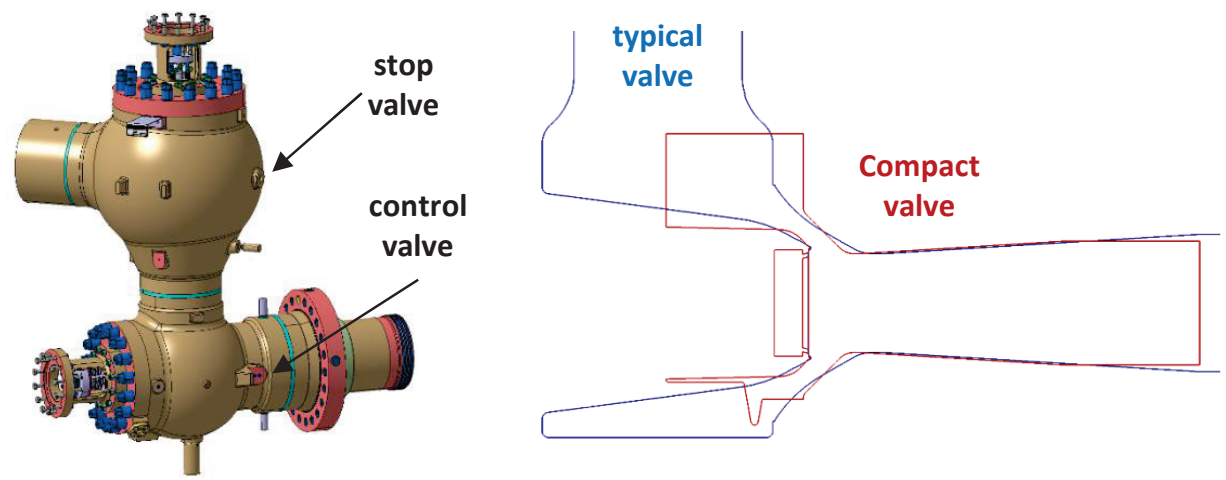

Fig. 1. Valve assembly of the intermediate-pressure turbine part (left), comparison between the valve chambers (right).

Table 1. Comparison of valve dimensions.

\begin{tabular}{|c|c|c|}
\hline & $\begin{array}{c}\text { compact valve } \\
\text { (IP valve) }\end{array}$ & $\begin{array}{c}\text { typical valve } \\
\text { (HP valve) }\end{array}$ \\
\hline $\boldsymbol{D}_{\mathrm{k}}[\mathbf{m m}]$ & 1,100 & 360 \\
\hline $\boldsymbol{D}[\mathrm{mm}]$ & 420 & 80 \\
\hline $\boldsymbol{\alpha}\left[^{\circ}\right]$ & $60,70,80,90$ & 60 \\
\hline $\boldsymbol{D}_{\mathrm{k}} / \boldsymbol{D}[\mathbf{1}]$ & 2.62 & 4.50 \\
\hline
\end{tabular}



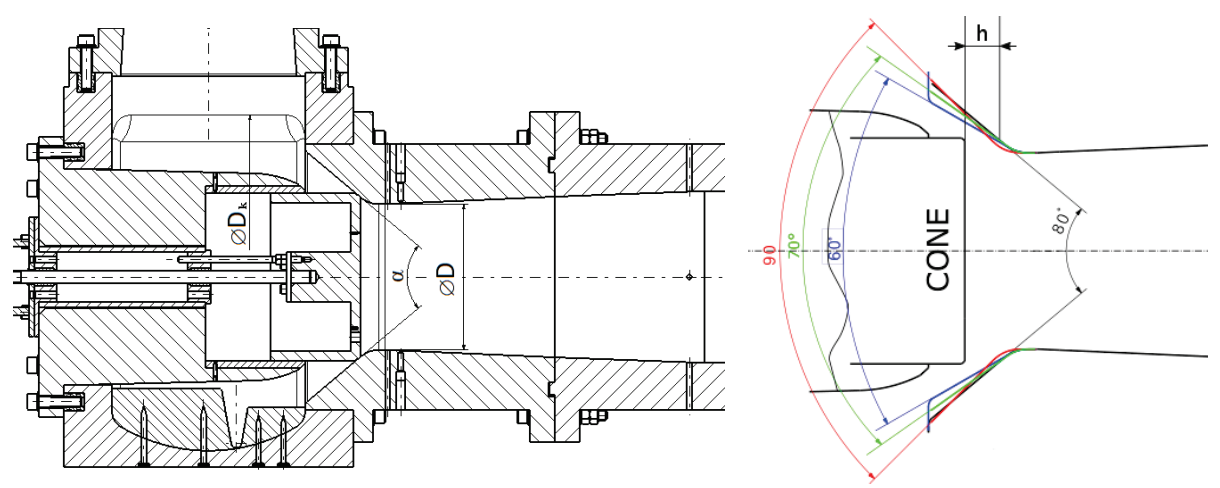

Fig. 2. Cross-section through the control valve model (left), valve seat angle $\alpha$ and valve cone lift $h$ (right).

For each valve assembly there are, among others, two objectives for research and development investigation. The first is to estimate pressure losses so that the turbine efficiency can be precisely calculated for all the similar valve designs. For this reason, pressure loss models are often created [4]. The second is to avoid a danger of intensive pressure oscillations because it can negatively affect valve operational reliability. The pressure oscillations can appear under the valve cone and near the diffuser side walls or even in the outlet part of the diffuser [9-11]. The issue is that these oscillations can cause high dynamic forces which can lead to strong valve vibrations and thus valve operating reliability failure. Therefore, each valve has to be designed very carefully to eliminate potentially unstable flow field, where pressure oscillations appear, for the required valve operating range. Therefore, except the pressure losses analysis, the pressure oscillation analysis is also an important part of this presented study.

\section{Experimental model}

The measured model representing the real valve assembly was scaled 1:2.875. It is sufficient to satisfy laboratory capabilities and the thermodynamic similarity theory [12]. The model consists of an inlet pipeline, a stop valve, a control valve and an outlet pipeline (Fig. 3). The detail cross-section is shown in Fig. 5. In order to measure a required range of flow conditions, a modular aerodynamic air tunnel situated in the Aerodynamic laboratory of the Institute of Thermomechanics of the Czech Academy of Sciences in Nový Knín in the Czech Republic was used. The scheme with a detail description of all parts is in Fig. 4. Measured flow conditions were defined by a mass flow rate and a control valve cone lift. The control valve is the main part of the presented study. Its design is new (compact) and it has to be operated under different valve cone lifts. The stop valve, design of which had been unified, has been analyzed in previous studies. Some results were published in [4]. 


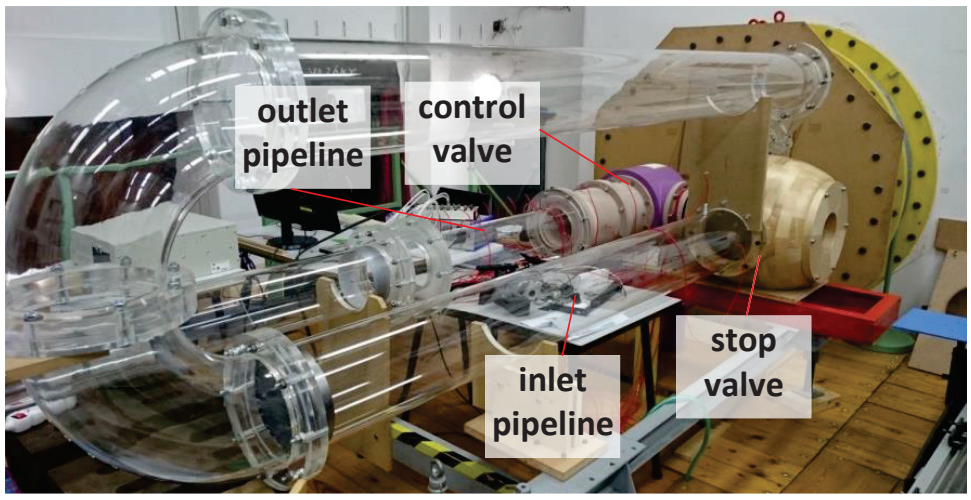

Fig 3. Model assembly in the laboratory.

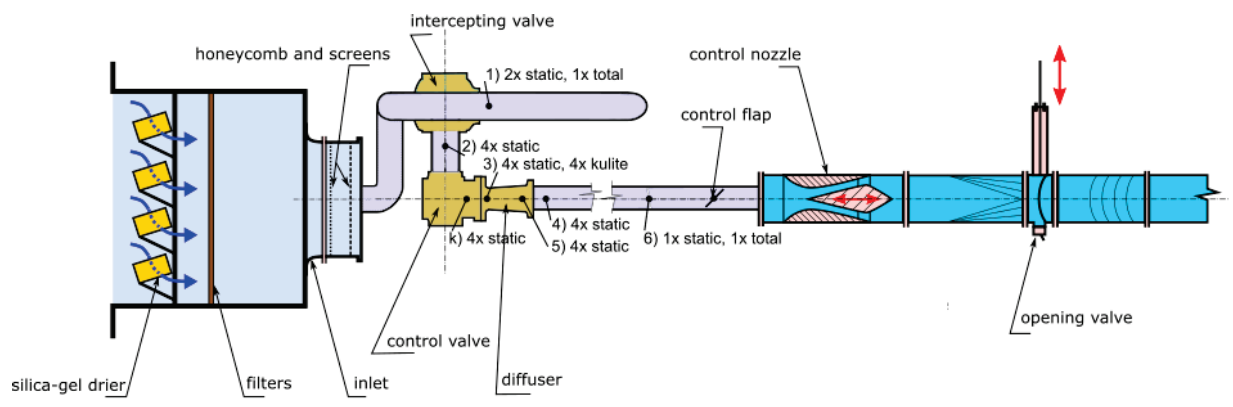

Fig. 4. Detail aerodynamic tunnel scheme.

The flow parameters were measured in different positions upstream, downstream and between the valves as it is depicted in Fig. 4 and in detail in Fig. 5. The mass flow rate was measured in the outlet pipeline using a system with Annubar probe and processing unit INMAT.. A total and static pressures upstream of the stop valve were measured by a Pitotstatic tube and wall static pressure taps. At each position from $p_{21}$ to $p_{54}$, there were four static pressure taps evenly distributed around the circumference [7]. These static pressures were measured by 16 channel pressure transducer NetScanner 9116. Pressure oscillations were measured by 4 fast response pressure transducers Kulite XCEL-100-1BARA near the valve diffuser throat (Fig. 5). The signal was amplified by modules DAQP-Bridge-A of Dewetron company and recorded by software Dewesoft with $14 \mathrm{kHZ}$ frequency. For each measured regime, the output signal was acquired for a period of 10s. From the measured time series, the root mean square (RMS) and power spectral density (PSD) were evaluated for each valve performed set of measurement using Matlab. PSD was evaluated by using Welch method with 1,024 samples in the Hann window with $50 \%$ overlap. To evaluate the intensity of the oscillations, the effective value of the RMS signal was used:

$$
\mathrm{RMS}=\sqrt{\frac{1}{N} \sum_{n=0}^{N} x[n]^{2}}
$$

Relative uncertainty of the total pressure loss coefficient evaluation is better than $4 \%$ with $95 \%$ confidence interval. Because the used medium is dry air, Reynolds numbers are lower in comparison with steam, which is in real valves, approximately by two orders of magnitude. 
Fortunately, previous internal studies and also publication [13] show that measurements at lower Reynolds numbers still provide accurate results. Effect of the different Reynolds number on total pressure losses will be probably the most significant in the diffuser. This may be one of the main source of differences between losses obtained experimentally and numerically.

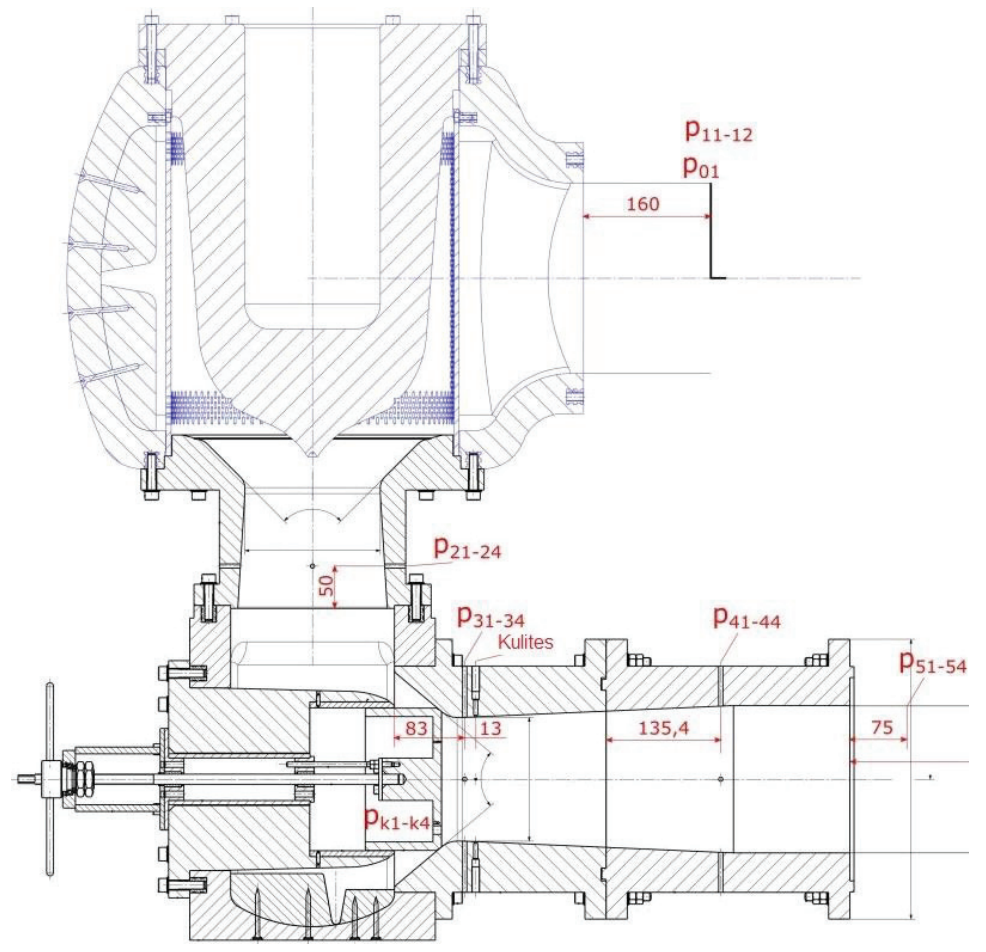

Fig. 5. Valve assembly model with measurement positions.

\section{Numerical model}

The numerical model (Fig. 6 on the left) was created according to the experimental one. A hexahedral as well as tetrahedral mesh (Fig. 6 on the right) was created to satisfy the typical mesh quality criteria and also the recommendation of the turbulence model to keep $y+<5$ [14]. It could be fulfilled thanks to the experiences in similar projects [4], [15]. The flowing medium was defined as dry air with thermodynamic parameters according to the experiment. A high resolution scheme was used to compute the steady state RANS solution with a compressible turbulent model. The k- $\omega$ SST turbulent model was used. Inlet and outlet boundary conditions were specified according to measured data. It means the total pressure and static temperature were defined at the model inlet and a static pressure at the model outlet in a way that static pressures at measured positions were in accordance with measured results. Simulation convergence criteria were quantified by $10^{-4}$ residual target value. In addition, the global mass flow rate imbalances and imbalances of required pressure losses were also monitored to be less than $0.1 \%$. More details are in [7]. 

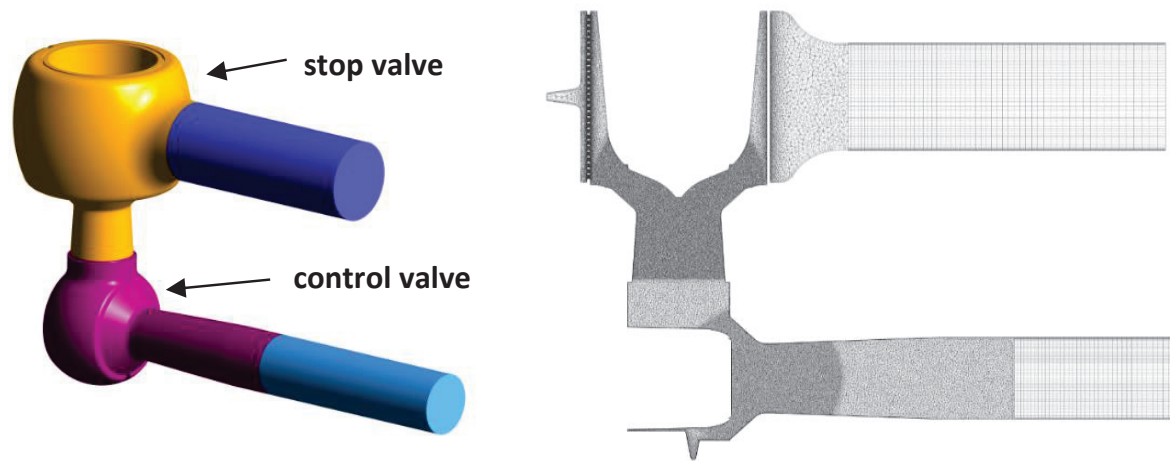

Fig. 6. Numerical model assembly (left), cross-section showing the used mesh (right).

\section{Results and discussion - valve characteristic}

A valve characteristic shows a dependence of three main different quantities: a mass flow, a pressure ratio and a valve cone lift. In order to generalize results, quantities in the form of $m / m_{\mathrm{cr}}, p_{5} / p_{2}$ and $h / D$ are used. $m$ is the measured mass flow rate, $m_{\mathrm{cr}}$ is the critical mass flow rate, $p_{5}$ is the static pressure downstream of the control valve (Fig. 5), $p_{2}$ is the static pressure upstream of the control valve (Fig. 5), $h$ is the valve cone lift and $D$ is the control valve diffuser throat diameter (Fig. 2). All the values are defined or measured except the $m_{\mathrm{cr}}$ which is related to the valve diffuser throat and calculated as:

$$
m_{c r}=A_{d i f} \sqrt{\frac{p_{2 t}}{v_{2 t}}} \sqrt{\gamma\left(\frac{2}{\gamma+1}\right)^{\frac{\gamma+1}{\gamma-1}}}
$$

Where $A_{\text {dif }}$ is the cross-sectional area of the diffuser throat, $p_{2 \mathrm{t}}$ is the total pressure at the control valve inlet, $v_{2 t}$ is the total specific volume at the control valve inlet and $\gamma$ is the heat capacity ratio.

The measured results evaluated in valve characteristics graphs for all valve seat angles from $60^{\circ}$ to $90^{\circ}$ are shown in Fig. 7 . The black line which reaches $m / m_{\mathrm{cr}}=0.3$ for $p_{2} / p_{5}=1$ represents a typical turbine characteristics and typical operating conditions of the valve. Therefore, the curves for each relative valve cone lift $h / D$ are the most important near this line for a practical use. When comparing the results of different angles but for the same relative valve cone lift (Figs. 8 and 9), it can be seen that for the same pressure ratio the greater the valve seat angle, the greater the mass flow. Having the same valve seat angles, this could show which case is better from the pressure losses point of view. However, when valve seat angles are different, which is this case, it does not mean that the valve with $\alpha=$ $60^{\circ}$ is the worst. The fact that the mass flow through the valve with $\alpha=60^{\circ}$ is the lowest is caused by the different mass flow. When having the same $h / D$, the valve with $\alpha=60^{\circ}$ has the smallest cross-section area ratio in comparison to the others (Tab. 2 on the left). In practice, the same mass flow should be achieved by the greater valve cone lift (Tab. 2 on the right). The results of $h / D=0.144$ and $\alpha=60^{\circ}$ showed in Fig. 9 on the right are very likely to be distorted by some unexpected measurement errors. It could be improved by repeating the measurement. However, it was observed far from the common valve operating conditions. 
Table 2. Different $A_{\text {seat }} / A_{\text {dif }}$ for the same $h / D$ (left) or different $h / D$ for the same $A_{\text {seat }} / A_{\text {dif }}$ (right) dependence on $\alpha$.

\begin{tabular}{|c|c|c|}
\hline $\boldsymbol{\alpha}\left[^{\circ}\right]$ & $\boldsymbol{h} / \boldsymbol{D}[\mathbf{1}]$ & $\boldsymbol{A}_{\text {seat }} / \boldsymbol{A}_{\text {dif }}[\mathbf{1}]$ \\
\hline 60 & 0.322 & 0.796 \\
\hline 70 & 0.322 & 0.921 \\
\hline 80 & 0.322 & 1.039 \\
\hline 90 & 0.322 & 1.145 \\
\hline
\end{tabular}

\begin{tabular}{|c|c|c|}
\hline $\boldsymbol{\alpha} \boldsymbol{~}^{\circ} \mathbf{]}$ & $\boldsymbol{A}_{\text {seat }} / \boldsymbol{A}_{\text {dif }}[\mathbf{1}]$ & $\boldsymbol{h} / \boldsymbol{D}[\mathbf{1}]$ \\
\hline 60 & 0.800 & 0.294 \\
\hline 70 & 0.800 & 0.258 \\
\hline 80 & 0.800 & 0.231 \\
\hline 90 & 0.800 & 0.211 \\
\hline
\end{tabular}
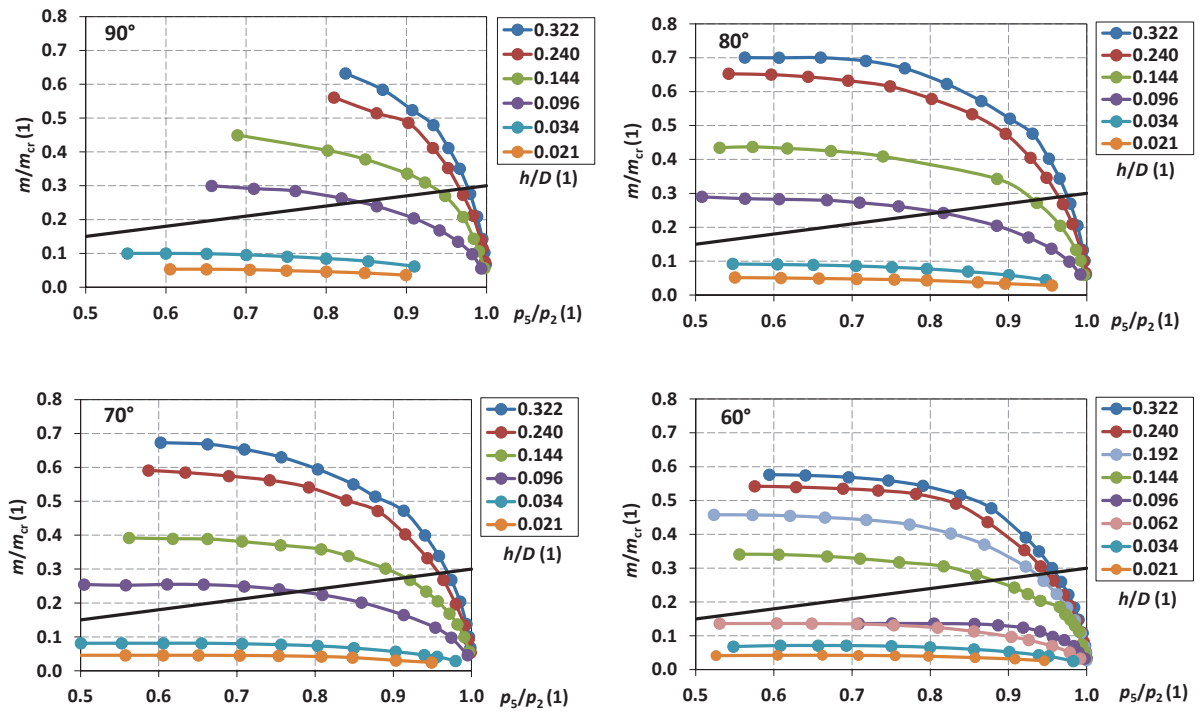

Fig. 7. Measured valve characteristics (curves for chosen relative valve cone lifts) for each valve seat angle.

The comparison of experimental and numerical data provides valuable information. Differences between experiment and CFD vary with changing operating conditions. It is shown in Fig. 10 where three different areas were identified according to results differences. The areas are roughly separated by dashed lines. The first region with the greatest differences appears for the greatest mass flows. In this region there are high velocities and both experimental and numerical inaccuracies are supposed to be greatest. Especially the mass flow measurement may be the most inaccurate there. The second is the area with greater numerical differences. They are caused by the fact that numerical simulations are carried out as steady-state, but phenomena such as flow detachment are very unsteady. This was proved by measurement as it is described in the following chapters. For this reason, the numerical results oscillate around some average value (Fig. 11 left). The results convergence was also not fully fulfilled in this area and the result is dependent on when the simulation was stopped. In the last region, differences between experiment and CFD are reasonable (Fig. 11 right). The maximal difference there is about $\pm 10 \%$ which is a very good agreement. It is the area around and below the typical turbine characteristic line when the validity of results is the most important. Similar results were also seen for lower relative valve cone lifts.

In general, inaccuracies of both experimental and numerical modelling which cause described differences are inherent. Except the measurement uncertainties which were already mentioned there are important uncertainties of numerical simulations. There can be a difference in the flowing medium. The thermodynamic properties are defined as calorically 
perfect ideal gas with a constant pressure specific heat capacity and Sutherland's formula for dynamic viscosity. This may be slightly different from reality. Other differences are caused by the assumption of perfectly smooth walls, the case is defined as adiabatic and there may be inaccuracies in the method used for turbulent flow modeling [16]. Main differences between experimental and numerical data probably result from the modelling of shear layers and their development. Especially when a flow separation appears, either mass flow rate or pressure ratio will be affected depending on the boundary conditions. However, regarding the fact that the numerical simulations are used mainly to better understand qualitative features of the flow in different flow regimes, the differences shown there are not supposed to be crucial.
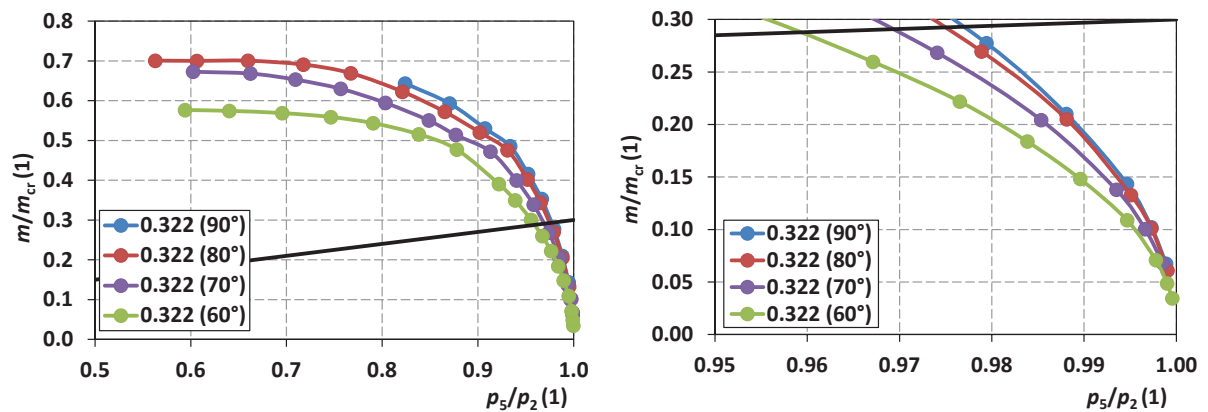

Fig. 8 Comparison of valve characteristics for $h / D=0.322$ for different $\alpha$-whole range (left), detail (right).
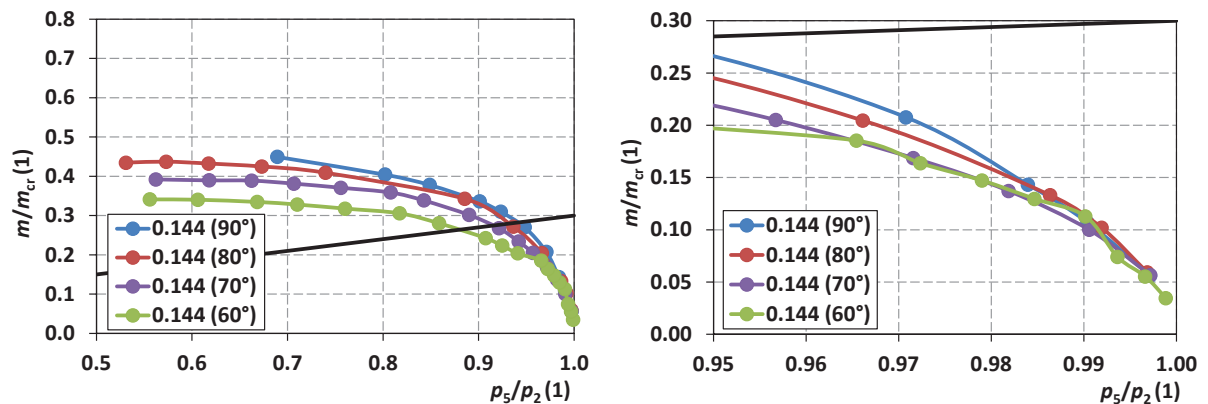

Fig. 9. Comparison of valve characteristics for $h / D=0.144$ for different $\alpha$-whole range (left), detail (right).

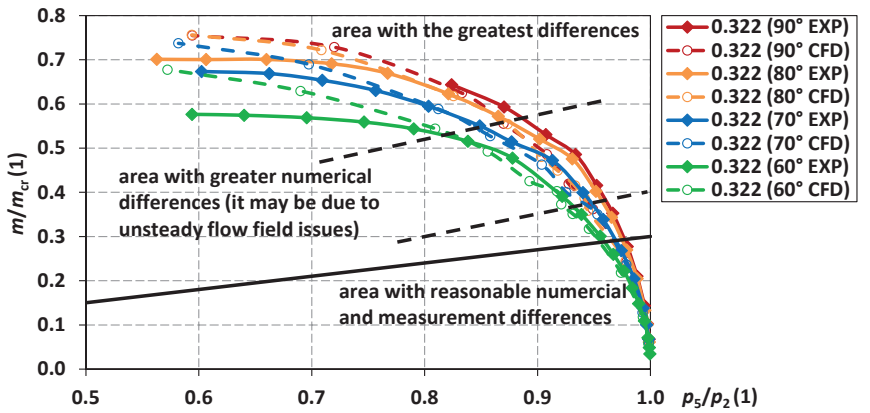

Fig. 10. Valve characteristics - comparison between experimental (EXP) and numerical (CFD) results for $h / D=0.322$. 

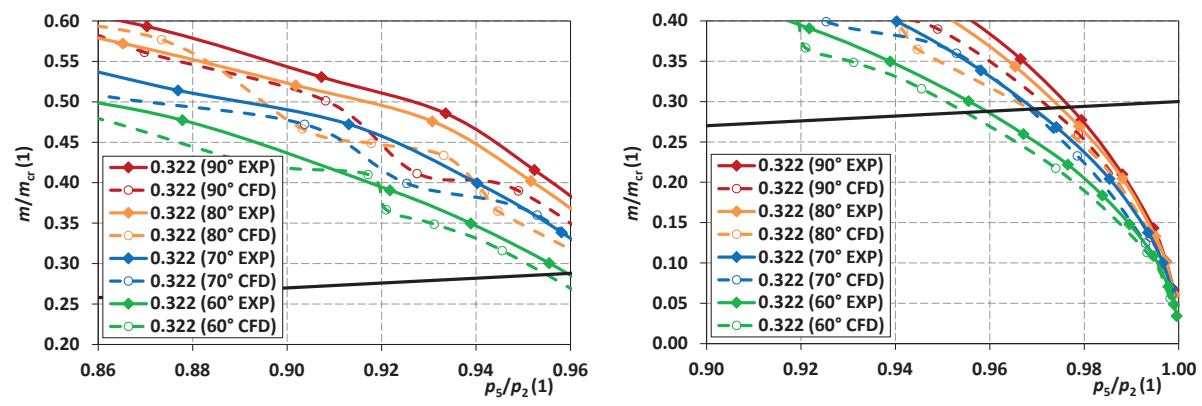

Fig. 11. Details of Fig. 10 - the area with greater (left) and reasonable differences (right).

\section{Results and discussion - pressure oscillations}

The pressure oscillations were evaluated as it is written in the previous chapter. An example of the raw measured data is in Fig. 12. From these raw dependences it is already evident that the amplitudes of pressure oscillations increase with decreasing pressure ratio and increasing valve cone lift. At relative valve cone lift $h / D=0.144$, there are visible abrupt changes (in the read oval in Fig. 12). These abrupt changes are very probably related to the abrupt flow detachment out of the diffuser walls very near or at the valve diffuser throat. It should be also noted that the change in the nature of oscillations was audible during the measurement sets. The same abrupt changes were also visible at relative valve cone lift $h / D=0.096$ (Figs. 13 and 14). For other relative valve cone lifts, this phenomenon was not observed.

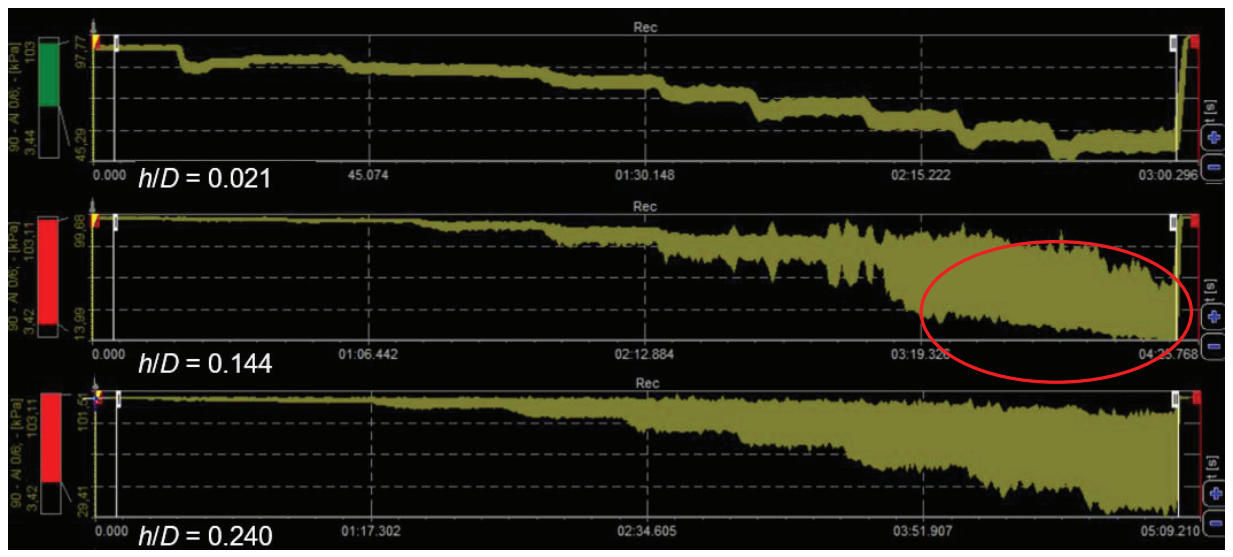

Fig. 12. Time record of pressures measured by a Kulite probe for the case with $\alpha=80^{\circ}$ for three different $h / D$ with an abrupt flow detachment identification (the red oval).

All the raw data, one example of which is in Fig. 12, were further transformed to the form of pressure oscillation maps in Figs. 13 and 14. There are also shown the cases with the observed abrupt pressure changes hence the probability of an abrupt flow detachment. For the purpose of this research, the magnitude of the pressure oscillations was characterized by the RMS value according to equation (3), which was determined as the maximum value ( $\left.\mathrm{RMS}_{\max }\right)$ from all four samples around the circumference of the valve diffuser throat. The results are shown in Figs. 13 and 14. There are again shown the curves for each relative valve cone lift (some of them have been already shown in Fig. 7) where each point has the $\mathrm{RMS}_{\max }$ value. 
Furthermore, the results were generalized to three modes which are shown by background colors for the cases with $60^{\circ}, 70^{\circ}$ and $80^{\circ}$ valve seat angle. For the $90^{\circ}$ valve seat angle there were not enough measured data for generalization hence it is not depicted. The blue color means range $0-2.7 \mathrm{kPa}$, the yellow $2.7-5.5 \mathrm{kPa}$ and the red $5.5-8.0 \mathrm{kPa}$. The important are again the black lines which show the typical turbine characteristic for $q_{\max }=m / m_{\mathrm{cr}}=0.3$.

It is clear from the maps in Figs. 13 and 14 that the smaller angle of the valve seat angle has a positive effect on the magnitude of the pressure oscillations. This is mainly reflected in the interval of the greatest values of $\mathrm{RMS}_{\max }$, which occur in the red areas. In addition, the observed abrupt pressure changes at $h / D=0.144$ and 0.096 are shifted to the left side of the graphs (towards lower pressure ratios) when valve seat angle decreases. From the operation reliability point of view, it is a good result because it is also far from the operating conditions where the valve is often used.
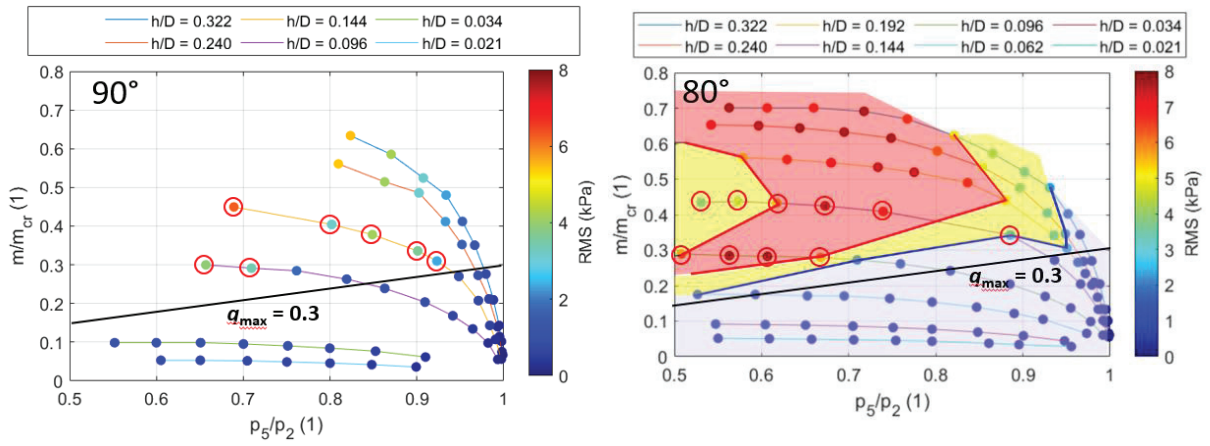

Fig. 13. Pressure oscillation maps (root mean square values) for $\alpha=90^{\circ}$ and $80^{\circ}$ with red marked points where there is expected an abrupt flow detachment.
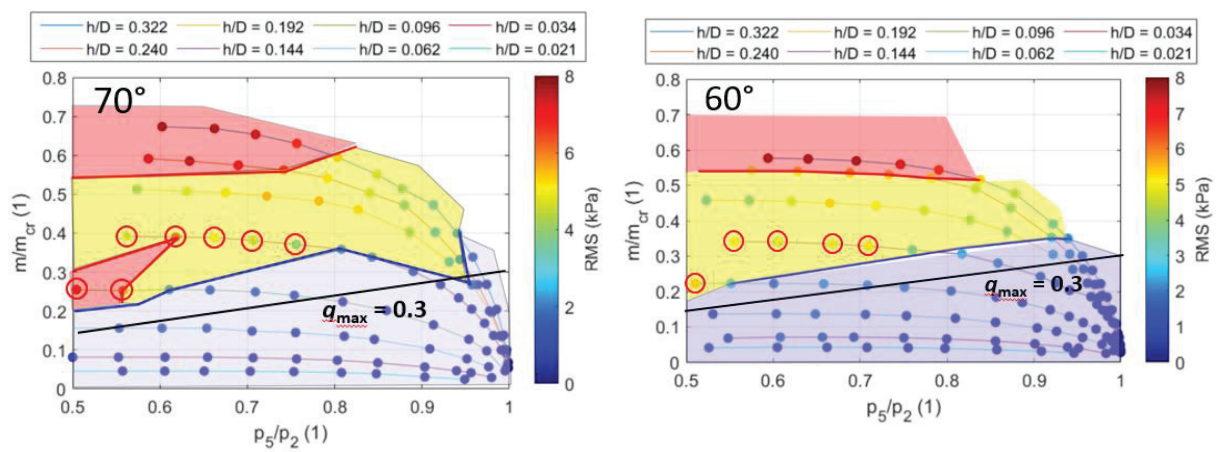

Fig. 14. Pressure oscillation maps (root mean square values) for $\alpha=70^{\circ}$ and $60^{\circ}$ with red marked points where there is expected an abrupt flow detachment.

In order to analyze what happens inside the flow field in detail, the numerical results can be used. The observed trends are shown on the example of the case with the valve seat angle $90^{\circ}$ for chosen mass flows and pressure ratios as well as for different relative valve cone lifts (Figs. from 15 to 17). Similar trends were visible for the other tested valve seat angles.

For the greatest valve cone lift $h / D=0.322$, the flow field is completely asymmetric no matter whether the valve is overloaded or not (Fig. 15). The flow field itself looks similar. The only difference is in velocity magnitudes. The non-uniformities can indicate that the 
valve design is not fully convenient for the case where the valve is fully opened. It means that there is a potential to reduce pressure losses by optimizing the geometry. Fortunately, the measured values indicating the significant pressure oscillations which can endanger the valve reliability are not high for less overloaded cases (Fig. 13). Therefore, even if the flow field is very asymmetric, the pressure oscillations are not significant. As a result, the valve can be used from operation reliability point of view. For lower valve cone lift $h / D=0.144$, the flow field is not too asymmetric, especially in case when the valve is less loaded (Fig. 16). From this case, it can be inferred that the lower the pressure ratio, the greater asymmetry and flow separations occur. It is in accordance with the measured pressure oscillations values which are also greater in the area with lower pressure ratios. However, it is still necessary to notice that there is the area where abrupt flow detachment can appear as shown in Figs. 13 and 14 . This phenomenon cannot be appropriately simulated by the numerical approach used in this study. The flow filed for such cases may look similar as it is in Fig. 16 on the right. For the lowest lift $h / D=0.021$, the flow field is fully symmetric no matter the pressure ratio (Fig. 17). It is also in accordance with measured results where the lowest pressure oscillations were observed.
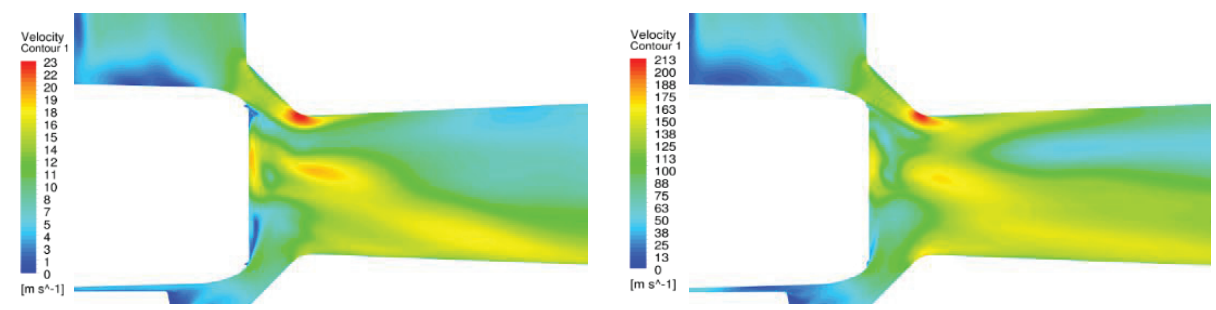

Fig. 15. Flow field in the valve cross-section for $\alpha=90^{\circ}, h / D=0.322, p_{5} / p_{2}=0.999$ for the less loaded case (left) and $p_{5} / p_{2}=0.833$ for the more loaded case (right).
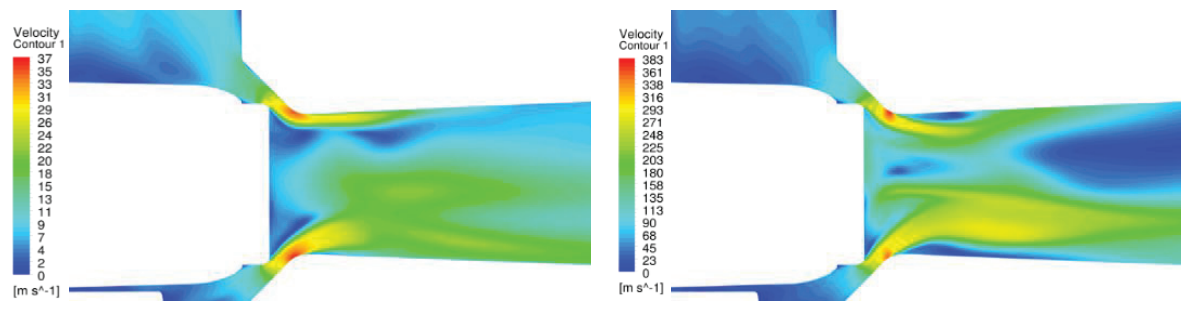

Fig. 16. Flow field in the valve cross-section for $\alpha=90^{\circ}, h / D=0.144, p_{5} / p_{2}=0.997$ for the less loaded case (left) and $p_{5} / p_{2}=0.690$ for the more loaded case (right).
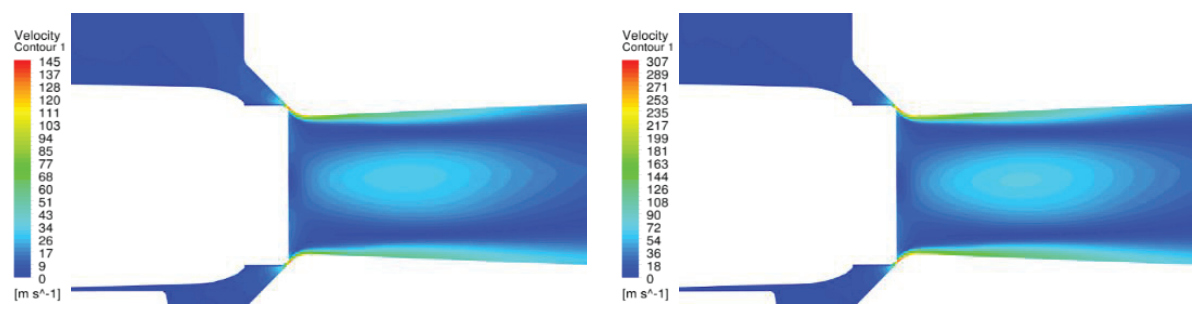

Fig. 17. Flow field in the valve cross-section for $\alpha=90^{\circ}, h / D=0.021, p_{5} / p_{2}=0.899$ for the less loaded case (left) and $p_{5} / p_{2}=0.605$ for the more loaded case (right). 


\section{Conclusions}

Aerodynamic measurements complemented with numerical simulations on the valve model of the compact valve assembly design for intermediate-pressure turbine parts reveal important knowledge of pressure losses which were evaluated in the form of valve characteristics and pressure oscillations which were evaluated in the form of pressure oscillation maps. It was carried out for four different valve seat angles $\left(60^{\circ}, 70^{\circ}, 80^{\circ}, 90^{\circ}\right)$ and whole range of pressure ratios as well as valve cone lifts. As a result, the following conclusions can be derived:

- Pressure losses were evaluated and compared. The lower the valve seat angle, the lower the mass flow. It is caused by the lower mass flow area under the valve cone.

- The comparison between the numerical and experimental results were described and there were identified the different areas according to the found differences. For the most important operating conditions (around the typical turbine characteristic), the differences are reasonable.

- For relative valve cone lifts $h / D=0.192$ or greater, the effective RMS value of pressure oscillations increases evenly with an increasing mass flow and decreasing pressure ratio. For relative valve cone lifts $h / D=0.144$ and $h / D=0.096$, there is an abrupt change in the RMS value of the signal at the certain mass flow and pressure ratio. This change is very probably related to the occurrence of a sudden flow detachment out of the diffuser walls very near to the valve diffuser throat.

- As the valve seat angle decreases, the area within the range of the highest RMS values decreases in the oscillating maps.

- Three different types of internal flow filed were identified. It was found out that there may be a potential to improve the valve design which would lead to pressure losses reduction.

Besides, thanks to this study, pressure losses in similar valve assemblies can be predicted with required accuracy for each new turbine and the areas of safe and dangerous operating conditions can be predicted so that the operational reliability of the valve can be guaranteed.

For the future investigation, at first, the results should be compared with other valve types, especially with those of relatively greater valve chambers in order to find out the differences in pressure losses and flow fields. As a consequence, the design of this compact valve would be optimized. Next, downstream of the valve assembly, there is a spiral inlet turbine chamber which leads steam to the turbine stages. In this turbine chamber inlet, the pressure losses have never been measured and compared with numerical results. There would be a potential to validate the pressure loss model for inlet turbine chambers as well as a possibility to optimize its design.

This research was made possible thanks to the kind support of the Technology Agency of the Czech Republic, National Center for Energetics TN01000007/05. The authors would also like to thank the Doosan Skoda Power Company and, the Institute of Thermomechanics of the Czech Academy of Sciences for giving a permission to publish this paper.

\section{References}

1. Kollross P., Tajc L.: An Experimental Research of the DSPW Steam Turbine Control Valve, AIP Conference Proceedings 2189, 020012, November (2019), https://doi.org/10.1063/1.5138624

2. Mrozek L., Tajc L., Vimmr J., Bublik O., Slama V., Kalista R., Dancova P.: The computational study in the unloading slot of the control valve, EPJ Web of Conferences 180, 02070 (2018), https://doi.org/10.1051/epjconf/201818002070 
3. Panuska M., Tajc L., Kollross P., Richter L., Volf M., Zitek P.: The effect of a strainer in the control valve of the steam turbine, AIP Conference Proceedings 2047:1 (2018), 020015, https://doi.org/10.1063/1.5081648

4. Slama V., Mrozek L., Tajc L., Simurda D., Hala J.: Creation and Validation of Pressure Loss Model for Steam Turbine Control Valves, AIP Conference Proceedings 2189, 020020, November (2019), https://doi.org/10.1063/1.5138632

5. Slama V., Mrozek L., Rudas B., Simurda D., Hala J., Luxa M.: Experimental and Numerical Study on Pressure Losses and Flow Fluctuations in a High-Pressure Valve Assembly of Steam Turbine Governing System, ASME Turbo Expo 2020, GT202014474, Virtual, Online conference, September (2020), https://doi.org/10.1115/GT202014474

6. Slama V., Mrozek L., Tajc L., Klimko M., Zitek P.: Flow Analysis in a Steam Turbine Control Valve with Through-Flow Valve Chamber, Journal of Nuclear Engineering and Radiation Science, NERS-20-1141, November (2020), https://doi.org/10.1115/1.4049055

7. Slama V., Mrozek L., Rudas B., Simurda D., Hala J., Radnic T.: Investigation of Pressure Losses and Flow Fluctuations in an Intercept Valve Assembly of an Intermediate-Pressure Turbine Part, ASME IMECE 2020, IMECE2020-23359, Virtual, Online conference, November (2020), https://doi.org/10.1115/IMECE2020$\underline{23359}$

8. Mrozek L., Slama V., Sedlak K., Tajc L.: Analysis of Losses in Steam Turbine Control Valves, AIP Conference Proceedings 2323, 060003 (2021), March 2021, https://doi.org/10.1063/5.0042097

9. Yueyue Li, Sihua Xu, Jin He, Zhiqiang Hu, Lei Xiao: Numerical Investigation on the Vibration of Steam Turbine Main Inlet Control Valves Considering Fluid Force Effects, ASME Turbo Expo 2019, GT2019-90419, Phoenix, Arizona, USA, June (2019), https://doi.org/10.1115/GT2019-90419

10. Windemuth C., Lange M., Mailach R.: Introduction of a Novel Test Rig for the Investigation of Fluid-Structure Interaction Effects in Steam Turbine Control Valves Using an Elastic Model, 13th European Conference on Turbomachinery Fluid Dynamics \& Thermodynamics, ETC2019-006, Lausanne, Switzerland, April (2019), https://www.euroturbo.eu/publications/proceedings-papers/etc2019-006/

11. Wallat S., Domnick B. C., Munch C., Brillert D.: A Test Rig Concept to Study Fluid Structure Interactions in a Steam Turbine Valve, ASME Turbo Expo 2018, GT201875094, Oslo, Norway, June (2018), https://doi.org/10.1115/GT2018-75094

12. Langhaar, H.: Dimensional analysis and theory of models, New York (1951)

13. Brüggeman P. et al.: A new emergency stop and control valves design - part 1: experimental verification with scaled models, ASME Turbo Expo 2014, GT201425116, Düsseldorf, Germany, June (2014), https://doi.org/10.1115/GT2014-25116

14. T. Knopp, Model-consistent universal wall-functions for RANS turbulence modeling, International Conference on Boundary and Interior Layers, Göttingen, Germany, January (2006).

15. Kalista R., Mrozek L., Slama V., Sedlak K.: Steam Turbine Axial Exhaust Diffuser Investigation Using a Test Rig and its Numerical Model, ASME IMECE 2019, IMECE2019-10267, Salt Lake City, Utah, USA, November (2019), https://doi.org/10.1115/IMECE2019-10267

16. Denton J. D.: Some Limitations of Turbomachinery CFD, ASME Turbo Expo (2010), Power for Land, Sea, and Air, Volume 7: Turbomachinery, Parts A, B, and C: 7 